\title{
Cyberbullying and its Relationship with Cognitive Distortions in Jordan
}

\author{
Abdalmuhdi Sawalha, \\ Irbid National University
}

\begin{abstract}
The study aimed to identify the level of both cyber bullying and cognitive distortions among a sample of Jordanian society in the Irbid city, and the relationship between them. The sample consisted of (2134) male and female. The results of the study showed that the level of cyber bullying and cognitive distortions came at a middle degree, and that there were statistically significant differences in the level of both cyber bullying and cognitive distortions according to the gender variable in favor of males, and in the variable of the nature of work the results showed that there were statistically significant differences in the level of cyber bullying in favor of (Student and unemployed), and in the level of cognitive distortions in favor of (unemployed). The results also showed that there were statistically significant differences in the level cyber bullying according to the age variable in favor (less than 18 years, and from 18- less than 30 years), and in the level of cognitive distortions in favor (less than 18 years). The results showed that there were no statistically significant differences in the level of both cyber bullying and cognitive distortions according to the variable of monthly income. The results also indicated that there is a positive statistically significant relationship between the cyber bullying and cognitive distortions.
\end{abstract}

Keywords:

Cyber Bullying, Cognitive Distortions, Jordanian Society, Irbid City

Article Received: 18 October 2020, Revised: 3 November 2020, Accepted: 24 December 2020

\section{Introduction}

Literature concerning the psychological, social, learning and technological issues among people from different ages have been widely discusses (Jdaitawi, Almutawa, Musallam, \& Talafha, 2014; Al-Mutawa et al., 2014; Maya Panoraman \& Malek, 2011; Ismael et al., 2015; Jdaitawi et al., 2013). The rapid development of electronic devices and communication applications has changed the way individuals socialized. Notably, the use of technology in our daily life aspects has exceeded the limits of the actual usage, as it becomes a source of concern and a threat to some individuals. Actually, the misuse of the Internet has become a key factor not only for cyberbullying but also for inducing and abusing minors, since their interactive and complex usage of Internet causes them to be more vulnerable to be targeted by ill-intentioned individuals.

Nowadays, the internet and social networks have become a strong competitor to the social upbringing institutions, such as family and school. Since we live in an era of social change and contemporary new technological influences such as the computer and the Internet, changes were not confined to a specific age group (Abu Abdullah, 2016). Cyberbullying is an intentional and violent act practiced by an individual or group using means of electronic communication repeatedly with a defenseless victim (Smith, Mandavi, Carvalho \& Tippett, 2005). Further, it is another form of traditional bullying and has a close relationship with it, as $30 \%$ of traditional bullies are cyberbullies ( $\mathrm{Li}, 2005)$.

Belsey (2008) defines cyberbullying as an individual's or group's usage of information and communication technology to support intentional repetitive hostile behavior with the aim of harming or abusing others. Willard (2007) defines it as the domination of others via sending or posting harmful information or engaging other forms of social domination using Internet or other digital technologies, such as smartphones. It is defined as a malicious, intentional communication throughout any form of technological devices such as Internet or mobile phones (Patchin and Hinduja, 2006). It is also defined as any intentional and recurrent aggressive behavior aims 
to harm others as a result of power imbalances (Olwes, 2012).

Willard (2003) has indicated that cyberbullying includes several forms, like: defamation, domination, harassment, discrimination, disclosure of personal information, posting information containing offensive or insulting comments, or impersonating an individual to work harm. Ybarra and Mitchell (2004) indicated that the use of anonymity on the Internet allows individuals to adopt a more aggressive personality than the one they might express in real life. Furthermore, stealing passwords, private internet connections with others and blocking someone from a chat room are also common forms of cyberbullying (Erdur-Baker and Kavşut, 2007).

Mograni (2018) asserts that there are two forms of cyberbullying. "Direct" represented in the use of the internet and smartphones in order to threaten or insult others; intentionally sending files containing viruses; or sending obscene and immoral pictures. And "Indirec" represented in browsing one's e-mail or abusing others through sending massages via e-mails or communication programs. As for Willard (2007), he states that cyberbullying has eight forms: hostile messages, bothering, defamation (insult), impersonation (posing as), divulging secrets, deception, blocking, and electronic harassment.

Cyberbullying is classified into four types: (1) Written, uses verbal bullying through calls, and verbal or written communication via text and electronic messages; (2) Visual, uses visual forms and images such as posting offensive or shameful images; (3) Blocking, represented by removing an individual from chat groups or conversations; (4) Impersonation, through stealing a person's identity and accessing his personal information, or using another person's account (Al-Shinnawi, 2014).

In fact, $93 \%$ of Internet users are currently minors, and thus the technologies using Internet has a key role in their social upbringing a thing that may not be positive in nature (Lenhart, Madden, Macgill and Smith, 2007). Furthermore, those minors may have several concerns as a result of the sequential effects of this cyber personal attack (Willard, 2007). Among the many Internet users were victims of cyberbullies and bullying (Ybarra, Mitchell, Finkelhor and Wolak, 2007; Juvonen and Gross, 2008; Arslan, Savaser, Hallett, and Balci, 2012; Zhou et al., 2013).

In their study, Berson, Berson and Ferron (2002) reported that $10.8 \%$ of adolescent girls in USA engaged activities fraught with danger on the Internet, such as sharing their personal information and sending their pictures to a person they met online or agreed to meet, and that few of them referred to exchanging suggestive or threatening messages. Victims and bullies have a series of psychological problems, such as frustration, grief, depression, feelings of guilt, self-harm, anxiety and distress (Mishna, Mclukie, and Saini, 2009). In their turn, bullies cause others to have many psychological problems, such as the fear of speaking out, anxiety about depriving them of their devices or Internet access, or the fear of scandal and being revealed (Mograni, 2018).

Technology and Internet users may have psychological, social and intellectual symptoms affecting all aspects of their lives, whereas the increased usage of the Internet may lead them to be socially isolated, have behavioral and cognitive disorders, and have seizures when their parents try to control the usage of technology and internet (Al-Abaji, 2010). Young (2005) believes that failure to fulfill these needs at childhood causes individuals to have personality disorders, whereas these unfulfilled needs may lead to the development of early maladaptive schemes.

Cognitive distortions are identified as cognitive outcomes or what an individual think about. The causal interpretation of an individual regarding some situations is the outcome of cognitive processes and related contents, furthermore the way in which an individual processes the information will have an impact on his/her emotional and behavioral responses and his/her 
general level of adaptation; i.e. if an individual processes external and internal information based on a negative scheme, his ability to face stressful situations would be affected, and thus having psychological disorders (Hamilton, 2015).

Cognitive distortion is a term used to describe a pattern of thinking or self-talk, whereas an individual thinks spontaneously about life events in a negative context lending to sadness, anger, shame, despair and anxiety feelings (Albin and Bailey, 2014). It is an exaggerated or irrational pattern of thought style contributes to the emergence and permanence of psychological disorders (Helmoud et al., 2015). It is also defined as biased or exaggerated patterns or beliefs that may be irrational or distorted, as it can frequently reinforce the negative thinking (Engler, 2014). Dozois and Beck (2008) also define it as negative, biased errors of thought that is said to increase susceptibility to disorder.

The dysfunctional cognitive structure of individuals underlies these cognitive distortions, as the cognitive distortions affecting interpersonal relationships are fueled by erroneous data recorded in cognitive schemes in early childhood, and they become active upon facing with difficult conditions in life (Weary and Edwards, 1994). These distortions are related to the way individuals originate as well as their belief system (Leung \& Poon, 2001). Al-Howaish (2010) asserts that it is a stream of erroneous, illogical thoughts characterized by their lack of objectivity and being based on expectations and subjective generalizations and on a mixture of suspicions, predictions, exaggerations, including: arbitrary conclusion, selective abstraction, overgeneralization, binary thinking, placing signs, reading minds, and intimidation and miniaturization.

Though, cognitive distortions are individuals' thoughts that cause an inaccurate perception of reality. According to Beck's cognitive model, negative perceptions or schemes are key factors in emotional dysfunction and impaired personal well-being. During difficult circumstances, distorted thoughts may contribute to a negative view of the surrounding world and a mental state of depression and anxiety (Grohol, 2009). Therefore, the exaggerated cognitive distortions of irrational thoughts cause psychological disorders. Cognitive distorted intellectuals usually distort their inner thoughts and tensions. They have a negative or pessimistic view of self, the world, and the future; in addition, they are characterized by a non-adaptive belief system that serves as a framework for their understanding and estimation of situations and issues. These individuals feel worthlessness and low levels of self-esteem causing them to develop psychological disorders. They see themselves as incompetent and believe that others do see them in this way. They have a fear towards future and are convinced that they are doomed to failure (Boury, Treadwell, and Kumar, 2001).

In their study, (Boury et al., 2001) reported that individuals with disorders often misinterpret facts and experiences in a negative way, as they limit their focus to situations' negative aspects, and thus a hopeless feeling towards future takes place. Abela and D'Alessandro (2002) claimed that individuals with dysfunctional attitudes are more likely to show an increase in the melancholic mood after an adverse event. Cognitive distortions related to relationships are classified as approach avoidance, unrealistic relationship expectations, and misunderstanding between individuals, whereas the mutual rejection among individuals creates negative expectations about others and includes negative thoughts about establishing close relationships with others (Hamamc1 and Büyüköztürk, 2003). Therefore, the unrealistic relationship carries high expectations for self, others and their attitudes, while the misunderstanding among individuals includes intellectual errors related to what others think and how they feel about an individual (Leahy, 2010). Researchers points out that distorted thoughts are the result of two things: 1 . The imaginary 
audience: an individual's belief that he/she is the focus of any social situation and that the audience's view is parallel to any opinion he/she has; 2. Personal myth: an individual's belief that he is safe, unique and has a privacy (Schwartz, Maynard, and Uzelac, 2008). The imaginary audience stems from the concept of personal myth, and both are associated with mood disorders and disorders-related behaviors (Beaudoin and Schonert-Reichl, 2006).

There are many types of cognitive distortions that afflict the thought, namely: "Black and White" thinking (polarized thinking), the exaggeration in blaming oneself and others, melancholic thinking, determinisms, mental selection (selective abstraction), overgeneralization, exaggeration and miniaturization, global labeling, jumping to conclusions, and superstitious thinking. The most prominent common cognitive distortions can be described as: selective abstraction; always being right; blaming; depreciating the positive; emotional reasoning; fallacy of change; misconceptions-regarding justice; mental filtering; jumping to conclusions; marking or highlighting of titles; exaggeration and underestimation; overgeneralization; personalization; shoulds; allor-nothing thinking (binary thinking); comparison; and catastrophizing (Reading the Future) (Corwin, Ruddle and Palmer, 2008; Grohol, 2009; Graham, 2014).

The Social Cognitive Theory holds that individuals interpret social situations using expectations, prior knowledge and assumptions, whereas most individuals do not realize their impact on their thinking, and thus fail to challenge their own interpretations of events, believing that they see the world professionally. The theory also holds that distorted thinking and dysfunction are the primary determinants of mood and behavior. Early cognitive behavioral approaches are of important in the clients' statements regarding situations and events that occur in daily life (Craske, 2010). It also emphasized the importance of cognitive factors, such as beliefs, self- perceptions, and expectations of social learning theory, whereas an individual can learn through observing others' actions and consequences. Although Bandura's theory of social learning emphasized (observation, modeling and selective reinforcement), his explanations for learning included, over time, a more interest in the cognitive factors, such as expectations, beliefs and the social influences of models (Holtz, 2011)

During cognitive therapy, latent theorists focus on the fact that an individual's feeling and behavior are determined by his / her perceptions and the nature of his/her self-experience. In addition to that, the theoretical assumptions of cognitive therapy indicate that the personal communication among individuals is greatly influenced by what is happening inside them. Since everyone gives a special meaning for his/her beliefs, it can be discovered and identified by him/her, rather than the cognitive therapist. Beck was interested in spontaneous thoughts that affect his thinking, and lead to the formation of false assumptions, which he has termed as "Cognitive Triad" (Corey, 2016). The cognitive triad contains negative thoughts that always cause turmoil, inflated distortions, and sense that these ideas are somewhat strange and out of the ordinary, as they seem to the individual correct, but cannot be proven in general by consensus because they are characterized by individual privacy.

Cognitive-behavioral theory focuses on how thinking interacts with what we feel and what we do. Therefore, it relies on the interaction of the way of thinking (perception), feeling (emotions), and acting (behavior). Negative and unrealistic thoughts can lead us to feel distressed and then having problems. When an individual suffers from psychological distress, the way he explains situations becomes skewed, and thus a negative impact the actions he/she takes. Cognitivebehavioral theory believes that abnormal behavior is a result of misconception of others through cognitive deficiencies (lack of planning) or cognitive distortions (inaccurate information 
processing), and that this perception causes distortions in the way we see things. In case the cognitive perceptions are inaccurate, or thinking is not enough, a disturbance of an individual's feelings and behavior may take place (Keefe, Chambless, Barber and Milrod, 2019).

However, few studies were conducted on the relationship between cyberbullying and cognitive distortions in general and adolescents in particular; and further studies are needed to explore the association between cyberbullying and cognitive distortions (Çelikkaleli and Kaya, 2016; Nyarko and Amissah, 2014; Owens, Skrzypiec and Wadham, 2014; Çoban and Karaman, 2013; Çetin, Peker, Eroğlu and Çitemel, 2011). Thus, this study is distinct from former ones in that it investigates the association between cyberbullying and cognitive distortions among a sample of Jordanian people. The current research provides a unique contribution by examining the relationship between cyberbullying and cognitive distortions.

\subsection{The Problem \& Questions of the Study}

One may view the Internet and the modern technology platforms as environments to express his/herself freely and establish social relations. With the development of electronic communication media and its rapid widespread use by all groups of society (especially minors who have digital skills as a result of keeping pace with it), the rate of cyberbullying may increase, especially with the emergence of social media applications. Nowadays, harming people via Internet has become easier and faster due to its accessibility by most individuals, even young, through smartphones containing all the modern applications. The misuse and the lack of parental controls and supervisions are among the negative effects on internet users in general, and minors in particular, since they are the pillars of future. In fact, some individuals having irrational views and attitudes tend to have distorted and weak social ideas and skills. As for other individuals having excessive self-confidence and unstable ambition, they tend to plunge into turmoil. In addition to that, the stressful socio-economic situations having multiple sources, severities, types and effects may also contribute to individuals' inability to achieve self-esteem and self-worth, as this may lead to behavioral and cognitive disturbances.

The problem is highlighted when things get out of control, whereas some of them fall into cyberbullying. The problem is also arising when they experience situations that are not commensurate with their ages. They may not realize the importance of preserving privacy and avoiding these situations that harm them. Furthermore, they also see, without any kind of supervision, pictures and videos that are inappropriate for their ages, as this may also offends them morally, psychologically and socially. Therefore, they end up in morbid stages at which they are unable to control themselves. Hence, the problem of the study stems from its attempt to identify cyberbullying and its relationship with cognitive distortions among a sample of the Jordanian community at Irbid city. However, five questions were formulated in this study which are as follows:

1- What is the level of cyberbullying among Jordanian people?

2- What is the level of cognitive distortions among Jordanian People?

3- Are there any significant differences between the participants characteristics in related to cyberbullying?

4- Are there any significant differences between the participants characteristics in related to cognitive distortions?

5- Is there any relationship between the cyberbullying and cognitive distortions among Jordanian people?

\section{Research Methods}

\subsection{Samples and Procedures}

In the current research, the author adopted a crosssectional data collection technique in the form of questionnaire survey. The survey method using 
quantitative tools to achieve the study objective, as consider suitable in social sciences studies and in gathering information on the participants belief and attitudes among large sample size (Jdaitawi, 2020; Malek, 2015; Ishak et al., 2011; Malek, 2019; Jdaitawi, 2020). A total of 2134 questionnaire copies were distributed to the study sample. From the 2172134 participants, 1198 $(56.1 \%)$ were male and $963(43.9 \%)$ were female. The participants ages fall into 4 categories, less than $18(721,33.8 \%), 18-30$ years old (832, $39.0 \%), 30-45$ years old $(369,17.3 \%)$, and more than 45 years old $(212,9.9 \%)$ participants. From 667 (31.3\%) participants identified themselves as students, $389(18.2 \%)$ as civil servant, 282 (13.2\%) working in the army and 796 (37.3\%) have no work. Lastly, the income of the participants ranged from less than 200 Jordan Dinar to more than 2000 Dinar.

\subsection{Measurements}

Cyberbullying Measurement: The selfadministered questionnaire items were gauged using a 36-item scale adopted from prior related literature (Gençdoğan and Çikrikci, 2015; Hussain, 2016; Aldhalaan, 2019; Topcu and Erdur-Baker, 2010). The reliability and validity of each scale were confirmed through several steps. The cyberbullying variable was utilized for measuring five dimensions, which are teasing, threaten, non-verbal cyberbullying, electronic hidden, and electronic self-learning. Each with different items numbers. The scale's Cronbach's alpha was reported to be 0.77 to 0.82 .

Cognitive Distortions: Cognitive distortions were measured using previous studies (Roberts, 2015;
Al-Jarah, 2020; Al-Shorman, 2020). A 44 items were used to identify the cognitive distortions among the study sample and were rated based on five likert-scale. The cognitive distortions variable was utilized for measuring eight dimensions. The reliability and validity of each scale were confirmed through several steps. Each sub-scale with different items numbers, and the scale's Cronbach's alpha was reported to be from 0.73 to 0.89 .

\section{Data analysis}

In order to answer the current study questions, several tests were conducted such as descriptive statistics, ANOVA test and Pearson Correlation.

1- What is the level of cyberbullying among Jordanian people?

In regard to question 1 , the statistical results showed that the mean and standard deviation of the cyberbullying measure among the participants are presented in table 1. From the results, it is clear that the study sample showed moderate level of cyberbullying, with a mean score of (3.47) and standard deviation (0.69). In regards to the cyberbullying dimensions, the results showed that the participants scored higher in electronic hidden dimension with a score of $(\mathrm{M}=3.61, \mathrm{SD}=0.57)$, followed by electronic teasing $(\mathrm{M}=3.54, \mathrm{SD}=$ 0.61 ), followed by non-verbal cyberbullying ( $\mathrm{M}=$ $3.49, \mathrm{SD}=0.67)$, threaten $(\mathrm{M}=3.43, \mathrm{SD}=0.64)$, and finally electronic self-learning with the mean score of $(\mathrm{M}=3.28, \mathrm{SD}=0.70)$ as shown in table 1 below, which indicated a moderate level on all of the cyberbullying dimensions. 
Table 1. Summary Statistics for cyberbullying and Its Dominions

\begin{tabular}{ll}
\hline \multirow{3}{*}{ cyberbullying } & Mean \\
electronic hidden & SD \\
electronic teasing & Mean \\
non-verbal cyberbullying & SD \\
threaten & Mean \\
& SD \\
electronic self-learning & Mean \\
& SD \\
& Mean \\
\hline
\end{tabular}

2- What is the level of cognitive distortions among Jordanian People?

In regard to question 2, the statistical results showed that the mean and standard deviation of the cognitive distortions measure among the participants are presented in table 2. From the results, it is clear that the study sample showed moderate level of cognitive distortions, with a mean score of (3.55) and standard deviation (0.63). In regards to the cognitive distortions dimensions, the results showed that the participants scored higher in arbitrary inferences dimension with a score of $(\mathrm{M}=3.71, \mathrm{SD}=0.53)$, followed by exaggeration $(\mathrm{M}=3.68, \mathrm{SD}=0.58)$, followed by generalized $(\mathrm{M}=3.65, \mathrm{SD}=0.62)$, self and other blames $(\mathrm{M}=3.60, \mathrm{SD}=0.59)$, wrong comparison $(\mathrm{M}=3.54, \quad \mathrm{SD}=0.64)$, underestimation $(\mathrm{M}=3.49, \mathrm{SD}=0.61)$, double thinking $(\mathrm{M}=3.44, \mathrm{SD}=0.69)$, and prediction the future $(\mathrm{M}=3.32, \mathrm{SD}=0.74)$ as presented in table 2 below, which indicated that the mean score of the cognitive distortions dimensions fallen in the moderate level.

Table 2. Summary Statistics for cognitive distortions and Its Dominions

$\begin{array}{cl}\text { cognitive distortions } & \text { Mean } \\ \text { arbitrary inferences } & \text { SD } \\ & \text { Mean } \\ \text { exaggeration } & \text { SD } \\ & \text { Mean } \\ \text { generalized } & \text { SD } \\ & \text { Mean } \\ \text { self and other blames } & \text { SD } \\ & \text { Mean } \\ \text { wrong comparison } & \text { SD } \\ & \text { Mean } \\ \text { Underestimation } & \text { SD } \\ & \text { Mean } \\ \text { double thinking } & \text { SD } \\ & \text { Mean } \\ & \text { SD } \\ \text { prediction the future } & \text { Mean } \\ & \text { SD }\end{array}$


3- Are there any significant differences between the participants characteristics in related to cyberbullying?

In regard to question 3, the statistical results showed that the mean and standard deviation of the cyberbullying measure among the participants are presented in tables below. Tables below showed a statistically significant differences between male and females in regard to cyberbullying at the level of sig. 050; but insignificant differences noticed for income levels on the cyberbullying variable. Regarding to occupation and age variables, Scheffe comparison were conducted. The results presented in table 5 showed that a significant difference exists between students and civil servant average, which evidenced that students scored higher. Furthermore, the results presented in table 6 showed that a significant difference exists on age variable between the average age of (less than 3045 years old) and (less than 18 and 18-30 years old). However, result evidenced that less than 18 years old and 18-30 years old scored higher than other groups.

Table 3. Summary Statistics for cyberbullying

\begin{tabular}{|c|c|c|c|}
\hline & & & cyberbullying \\
\hline Gender & Male & Mean & 3.85 \\
\hline & & SD & 0.71 \\
\hline & Female & Mean & 3.64 \\
\hline & & SD & 0.80 \\
\hline Age & less than 18 & Mean & 3.87 \\
\hline & & SD & 0.63 \\
\hline & $18-30$ years & Mean & 3.93 \\
\hline & & SD & 0.59 \\
\hline & $30-45$ years & Mean & 3.75 \\
\hline & & SD & 0.70 \\
\hline & More than 45 & Mean & 3.79 \\
\hline & & $\mathrm{SD}$ & 0.68 \\
\hline Job & Student & Mean & 3.78 \\
\hline & & SD & 0.69 \\
\hline & Civil Servent & Mean & 3.66 \\
\hline & & $\mathrm{SD}$ & 0.75 \\
\hline & Army & Mean & 3.63 \\
\hline & & SD & 0.81 \\
\hline & Non & Mean & 3.81 \\
\hline & & SD & 0.67 \\
\hline Income & $<200 \mathrm{JD}$ & Mean & 3.71 \\
\hline & & SD & 0.65 \\
\hline & 200-500JD & Mean & 3.69 \\
\hline & & SD & 0.71 \\
\hline & 500-1000JD & Mean & 3.74 \\
\hline & & SD & 0.62 \\
\hline & 1000-2000JD & Mean & 3.66 \\
\hline & & SD & 0.74 \\
\hline & $>2000 J D$ & Mean & 3.70 \\
\hline & & SD & 0.68 \\
\hline
\end{tabular}


Table 4. Results of Four Way-ANOVA of the Research Variables

\begin{tabular}{|c|c|c|c|c|c|c|c|}
\hline Source & Variables & $\begin{array}{l}\text { Sum of } \\
\text { Squares }\end{array}$ & & df & $\begin{array}{l}\text { Mean } \\
\text { Square }\end{array}$ & $\mathbf{F}$ & $\mathbf{P}$ \\
\hline & Gender & 1.967 & 1 & 1.967 & $\begin{array}{ll}6.249 & 0.000\end{array}$ & & \\
\hline & Occupation & 6.438 & 3 & 2.146 & 5.266 & & \\
\hline & Age & 5.202 & 3 & 1.734 & 7.012 .000 & & \\
\hline & Income & 2.468 & 4 & 0.617 & $\begin{array}{ll}0.985 \quad .867\end{array}$ & & \\
\hline & Error & 63.549 & 2122 & 0.030 & & & \\
\hline & Total & 74.522 & 2133 & & & & \\
\hline
\end{tabular}

Table 5. Scheffe Test Results on Occupation Comparisons for cyberbullying

\begin{tabular}{|c|c|c|c|c|}
\hline Occupation & Student & Civil Servant & Army & No Job \\
\hline Mean & 3.78 & 3.66 & 3.63 & 3.81 \\
\hline$\overline{\text { Student }}$ & 3.78 & & & \\
\hline Civil Servant & 3.66 & $0.41^{*}$ & & \\
\hline Army & 3.63 & 0.10 & 0.09 & \\
\hline No Job & 3.81 & 0.12 & $0.36^{*}$ & 0.07 \\
\hline
\end{tabular}

Sig. 0.05

Table 6. Scheffe Test Results on Age Comparisons for cyberbullying

\begin{tabular}{lllll}
\hline Age & Less than 18 & $18-30$ Years & $30-40$ Years & More than 45 years \\
\hline Mean & 3.87 & 3.93 & 3.75 & 3.79 \\
\hline Less than 18 & 3.87 & & & \\
18-30 Years & 3.93 & 0.10 & & \\
30-40 Years & 3.75 & $0.32^{*}$ & $0.39^{*}$ & \\
More than 45 years & 3.79 & 0.08 & 0.13 & 0.09 \\
\hline
\end{tabular}

Sig. at 0.05

4- Are there any significant differences between the participants characteristics in related to cognitive distortions?

In regard to question 4, the statistical results showed that the mean and standard deviation of the cognitive distortions measure among the participants are presented in tables below. Tables below showed a statistically significant differences between male and females in regard to cognitive distortions at the level of sig. 050; but insignificant differences noticed for income levels on the cognitive distortions variable. Regarding to occupation and age variables, Scheffe comparison were conducted. The results presented in table 5 showed that a significant difference exists between students and civil servant average, which evidenced that students scored higher. Furthermore, the results presented in table 6 showed that a significant difference exists on age variable between the average age of (less than 3045 years old) and (less than 18 and 18-30 years old). However, result evidenced that less than 18 years old and 18-30 years old scored higher than other

groups 
Table 7. Summary Statistics for cognitive distortions

cognitive distortions

\begin{tabular}{|c|c|c|c|}
\hline \multirow[t]{4}{*}{ Gender } & Male & Mean & 3.76 \\
\hline & & $\mathrm{SD}$ & 0.74 \\
\hline & Female & Mean & 3.69 \\
\hline & & $\mathrm{SD}$ & 0.79 \\
\hline \multirow[t]{8}{*}{ Age } & less than 18 & Mean & 3.94 \\
\hline & & $\mathrm{SD}$ & 0.54 \\
\hline & $18-30$ years & Mean & 3.68 \\
\hline & & $\mathrm{SD}$ & 0.67 \\
\hline & $30-45$ years & Mean & 3.76 \\
\hline & & $\mathrm{SD}$ & 0.59 \\
\hline & More than 45 & Mean & 3.71 \\
\hline & & $\mathrm{SD}$ & 0.64 \\
\hline \multirow[t]{8}{*}{ Job } & Student & Mean & 3.66 \\
\hline & & $\mathrm{SD}$ & 0.69 \\
\hline & Civil Servent & Mean & 3.61 \\
\hline & & SD & 0.75 \\
\hline & Army & Mean & 3.64 \\
\hline & & $\mathrm{SD}$ & 0.73 \\
\hline & Non & Mean & 3.83 \\
\hline & & $\mathrm{SD}$ & 0.62 \\
\hline \multirow[t]{10}{*}{ Income } & $<200 \mathrm{JD}$ & Mean & 3.70 \\
\hline & & $\mathrm{SD}$ & 0.74 \\
\hline & 200-500JD & Mean & 3.75 \\
\hline & & $\mathrm{SD}$ & 0.66 \\
\hline & 500-1000JD & Mean & 3.72 \\
\hline & & $\mathrm{SD}$ & 0.69 \\
\hline & 1000-2000JD & Mean & 3.69 \\
\hline & & $\mathrm{SD}$ & 0.77 \\
\hline & $>2000 J D$ & Mean & 3.77 \\
\hline & & $\mathrm{SD}$ & 0.61 \\
\hline
\end{tabular}

Table 8. Results of Four Way-ANOVA for of the Research Variables

\begin{tabular}{llllllll}
\hline Source & Variables & $\begin{array}{l}\text { Sum of } \\
\text { Squares }\end{array}$ & & df & $\begin{array}{l}\text { Mean } \\
\text { Square }\end{array}$ & F & P \\
& & & & & & & \\
& Gender & 1.468 & 1 & 1.468 & 7.349 & 0.000 & \\
& Occupation & 7.249 & 3 & 2.146 & 4.967 & 0.000 & \\
& Age & 6.912 & 3 & 2.304 & 8.135 & .000 & \\
& Income & 2.126 & 4 & 0.532 & 0.761 & .536 & \\
& Error & 59.218 & 2122 & 0.028 & & & \\
& Total & 70.927 & 2133 & & & & \\
& & & & & & & \\
$* *$ & & & & & & &
\end{tabular}


Table 9. Scheffe Test Results on Age Comparisons for cognitive distortions

\begin{tabular}{lllll}
\hline Age & Less than 18 & $18-30$ Years & $30-40$ Years & More than 45 years \\
\hline Mean & 3.94 & 3.68 & 3.76 & 3.71 \\
\hline Less than 18 & 3.94 & & & \\
18-30 Years & 3.68 & 0.09 & & \\
30-40 Years & 3.76 & 0.11 & 0.13 & 0.07 \\
More than 45 years & 3.71 & $0.29^{*}$ & 0.10 & \\
\hline
\end{tabular}

Sig. 0.05

Table 10. Scheffe Test Results on Occupation Comparisons for cognitive distortions

\begin{tabular}{|c|c|c|c|c|}
\hline Occupation & Student & Civil Servant & Army & No Job \\
\hline Mean & 3.66 & 3.61 & 3.64 & 3.83 \\
\hline$\overline{\text { Student }}$ & 3.66 & & & \\
\hline Civil Servant & 3.61 & 0.11 & & \\
\hline Army & 3.64 & 0.08 & 0.07 & \\
\hline No Job & 3.83 & $0.36^{*}$ & 0.13 & 0.10 \\
\hline
\end{tabular}

Sig. 0.05

5- Is there any relationship between the cyberbullying and cognitive distortions among Jordanian people?

In regard to question 5, the results in table 11 contains all the correlation analysis results of the variables. From the table, it is clear that cyberbullying had positive and significant relationship with cognitive distortions. In addition, the results showed that cyberbullying daimonions positively associated with cognitive distortions dimensions as shown in table 11 below.

Table 11. Summary of Correlation between Variables

\begin{tabular}{llllll}
\hline Measure & $\begin{array}{l}\text { electronic } \\
\text { Hidden }\end{array}$ & \multicolumn{2}{c}{$\begin{array}{c}\text { electronic } \\
\text { teasing }\end{array}$} & \multicolumn{2}{c}{ non-verbal } \\
cyberbullying & \multicolumn{2}{c}{ threaten e-Self Learning } \\
\hline arbitrary inferences & $0.18^{* *}$ & $0.35^{*}$ & $0.32^{* *}$ & $0.38^{* *}$ & $0.30^{* *}$ \\
exaggeration & $0.24^{* *}$ & $0.32^{*}$ & $0.24^{* *}$ & $0.23^{*}$ & $0.23^{*}$ \\
generalized & $0.28^{* *}$ & $.37^{* *}$ & $0.32^{* *}$ & $0.42^{* *}$ & $0.26^{* *}$ \\
self and other blames & $0.27^{*}$ & $0.31^{* *}$ & $0.30^{* *}$ & $0.34^{* *}$ & $0.26^{* *}$ \\
wrong comparison & $0.30^{* *}$ & $0.29^{* *}$ & $0.22^{* *}$ & $0.27^{* *}$ & $0.19^{* *}$ \\
Underestimation & $0.37^{* *}$ & $0.45^{* *}$ & $0.26^{* *}$ & $0.35^{* *}$ & $0.21^{* *}$ \\
double thinking & $0.23^{* *}$ & $0.20^{* *}$ & $0.28^{* *}$ & $0.31^{* *}$ & $0.30^{*}$ \\
prediction the future & $0.43^{* *}$ & $0.50^{* *}$ & $0.48^{* *}$ & $0.41^{*}$ & $0.51^{* *}$ \\
\hline
\end{tabular}

Note: $* \mathrm{p}=<.05$

\section{Discussion}

The result of the study showed that cyberbullying among individuals in the Jordanian society was moderate; something that can be explained by the burdens resulting from their social conditions leading to psychological and emotional stresses. This leads to more use of social communication media to ventilate their energies and stresses. Additionally, modern communication media allows users to hide their true identity, making 
them practice bullying without fearing being legally prosecuted for this behavior. Social communication media also enables individuals to interact with others without verifying their true identity or their age. These media also provide means respond and to practice bullying without being directly in contact with the other party. Students also do not have much experience related to electronic identity theft or assaulting another person using an allies name requiring school measures or even legal ones.

The result of the study showed that cognitive distortions among individuals was moderate which may be due to the social, cultural and intellectual socialization of the society the individual belongs to. It may also be said that personal experience is a key factor in developing believes and ideas leading individuals to formulate negative images and ideas towards themselves, others and the future. Since the experiences lived by the individual take their miserable, sad and defeating meanings when being integrated with the negative opinions and explanations one holds about himself, others and the future, he eventually develops a believe leading to distorting the relating negatively as one makes stable cognitive schemes, he indorses about himself. When being developed, an individual interacts with events with over exaggeration since they look to things and events in illogical and irrational. The sample of the study adopts negative attitudes to confront difficulties. Knowing that the majority of the society started the consequences of strategic events years ago, this had a negative effect on their ideologies.

The results showed that males reported higher levels of cyberbullying, a logical result consistent with previous studies. It may be contended that males are more capable than females to express tense emotions such as rage compared to females; and that males in the Arab world -According to the prevalent traditions- allow males to use social communication media more than females. Furthermore, males have more opportunities to contact with strangers and communicate with them while the majority of females do not trust strangers and block them from accessing to their private accounts on social communication websites. Consistent with their biological and emotional nature, females are more cautious to use some behaviors such as cursing and assaulting others via social media. Finally, they do not trust privacy insurance procedures used in social media and this result from their fear of the community if their social media identity is disclosed before others.

The results that male students reported higher levels of cyberbullying compared to females may be attributed to the fact that the percentage of males owing smart phones is much higher compared to females. In this sense, they are more able to engage in social media activities. Additionally, inter-communication using social media is higher compared to females as communicating and meeting new friends using social media has become a common behavior among males. Also, males show higher levels of distress and emotionality, and impulsivity; something making them employee social communication media to bully others. The researcher also contends that nomophobic behavior among males is higher since it provides a fast way to blend with others. Social media tools have a great power to attract males' attention.

The results of the study showed that unemployed individuals showed higher levels of cyberbullying compared to employed individuals. This result may be attributed to that these people face burden related issues and concerns as they are goalless and do not have any meaning of their life. This emptiness may lead to developing several emotional and behavioral disorders. New technologies have opened unproceeded ventures for such people to fulfill their time. When knowing that unemployed individuals feel that their self-worth in life is very low; are unable to capitalize the potentials provided by new technologies when seeking for information able to 
fulfill their desires and tendencies as a result of feeling lonely, such emotions have a negative effect on the individual and the whole society since he spends most of his time on misbehaviors such as cyberbullying others.

The results indicated that age group less than 30 showed the highest level of cyberbullying; something that may be explained by the fact that cyberbullying is a behavior reflecting a psychological state and ethical education, crises that many children and adolescents suffer from due to what they are exposed of violence, deprivation and suppression, showing cyberbullying by cursing others using inappropriate language may be a type of response to these stressors.

The results also showed that there is no statistically significant difference due to family income in cyberbullying level. This result may be due to that the social and cultural environment of the sample is relatively similar. The socioeconomic conditions of Irbid city residence provide a suitable climate for each individual to grow normally in a fair and trustworthy surrounding. This fact emphasizes the vital rule of the general climate of the society prevailing at Irbid city leading to not finding statistically significant differences in cyberbullying due to family income.

The results showed that males had higher scores on the cognitive distortion scale used in this study; a result that may be explained by that this form of disorders is the consequences of various stressful environmental circumstances. The negative environmental and painful circumstances combined with the socialization nature of males compared to females either by the family, educational institution and career organization in addition to the society pro-males' trends as they are more exposed to installing distorted ideas and believes, leading to the aberrance of different psychological, social and emotional issues. When knowing that cognition controls feelings and emotions, and this explains the by-directional relationships between cognition and emotions combined with the fact that dysfunctional feelings and emotions produced by various stressors combined with parenting styles; all of these indicate that there is cognitive distortion among individuals. As a result of the numerous problems male adolescents face and due to the negative environmental experiences, they are exposed, they are more likely to form cognitive distortion. In the same vein, families endorse some distorted ideas that may lead to maximizing the emotional and behavioral problems among children due to negative parenting styles, especially males.

In the same line, the study showed that unemployed individuals reported higher levels of cognitive distortion as they are more prone to maintain self-blame, criticizing, develop negative feelings about themselves in addition to anticipating catastrophes, lose hope, show more tendencies towards scepticism, over exaggerate the consequences of the events, over generalize things and adopt selective visions leading to develop misconceptions which drives them to indorse a negative attitude toward themselves, the surrounding world and the future. All of this leads to chronic feelings of guilt, anxiety, low selfesteem, frustration, and helplessness, which may develop some time to showing neuroticism and aggression. They are more likely to form distorted stable cognitive schemes having negative effect on their cognitive information processing and their perceptions about themselves and the surrounding world. There assumptions and explanations are also negatively affective which may result in producing spontaneous ideas that in term interact with their behaviors and emotions. This finally leads to developing to organize distortions that make the individual unable to use effective methods in information processing.

The results of the study reported that age group less than 18 reported higher levels of cognitive distortions, which may indicate that they show negative behaviors due to their inability to adjust and self-control. This may imply that they have a 
latent cognitive structure a companying these behaviors, which may be reflected on their desires. This cognitive distortion may be seen in using negative conceptions about self and in low self-respect and self-esteem, looking at oneself as an incomplete person having no self-worth, and that he is the main source of problems he is suffering now. This age group did not reach full maturity as they are still very attached with their early years and show some immature ideas that may be considered normal in previous years. They are still giving much or less worth to things and events as this worth is different from what others give to them. They blame themselves on negative events that take place in the past and they have nothing to do with them. They may also concentrate on other people as the source as their negative feelings, refusing at the same time to hold complete responsibility in changing themselves. This result is different from the results reported by Nyarko and Amissah (2014) which showed that there are no statistically significant differences in cognitive distortion in light of age, as well as the study of Çoban and Karaman (2013) which found that there are statistically significant differences in the level of cognitive distortion in light of age, in favor of the age group (21-25).

The study showed no statistically significant differences in cognitive distortion level due to family income as the cultural and social circumstances lived by Irbid city residence canceled the economic boundaries among people in the city. This result can be also explained to the socialization as they are exposed to similar family interactions, common parenting styles and they live in similar family environment. Since families at Irbid city share the same ideas and values, the effect of such factors is relatively stable. On the other hand, this result may be attributed to the fact that people in general jump to conclusion without thinking deeply without thinking about the consequences of their actions and in most times show tendencies in generalization when using different word and sentences try to impose their perceptions on others as they falsely think that others showed listen to them and act accordingly.

The study found a statistically significant correlation between cyberbullying and cognitive distortions which may be attributed to that cognitive distortion among individuals is highly related to showing cyberbullying in real life. The tendency to show cyberbullying may be reinforce indirectly when people see that they are praised when showing these dysfunctional behaviors. Individuals showing delinquent and deveined behaviors learn them the same way others learn it. The bully may adopt different behavioral models that may not be accepted by the other members of the society. Bullies usually develop bullying as a behavior by imitating others in the surrounding environment whether in family, at school or seeing peers. They may develop bullying from the stories they read or get some misguided information they use to justify their bullying. This is part of the misconceptions leading to cognitive distortions. The researcher explain the correlation between cognitive distortion and cyberbullying by that bullies have negative perceptions about themselves and others and they are more vulnerable to develop psychological disorders as such, their cognitive distortions are more likely to be higher compared to others. The result is consistent with the results reported by Owens and his colleagues (2014) who found that cognitive distortion is high among bullies and the victims of bullying. The result also consistent with the result of Çetin and his colleagues (2011) which showed that cyberbullying has been positively correlated to cognitive distortions.

\section{References}

[1] Abela, J. \& D'Alessandro, D. (2002). Beck's cognitive theory of depression: A test of the diathesis-stress and causal mediation components. British Journal of Clinical Psychology, 41, 111-128. 
[2] Alabaji, O. (2010). Internet and addiction. Dar Majdalawi Publisher \& Distribution, Amman, Jordan.

[3] Albin, J. \& Bailey, E. (2014). Cognitive behavioral therapy. New York: Penguin Group.

[4] Aldhalaan, M. (2019). Cyber bullying and its relation to the level of awareness of digital practices in a sample of secondary school students in the northern border regions. Journal of Humanities and Applied Social Sciences, 1 (2), 19-36.

[5] Aljarrah, R. (2020). Self-esteem contributions and cognitive distortions and other personal factors on prediction personality disorder among Yarmouk university students. Unpublished Doctoral Dissertation, Yarmouk University, Jordan.

[6] Al-Mutawa, A., Jdaitawi, M., Saleh, W., \& Awwad, A. (2014). Psychological strain among academic staff in Eastern Saudi Arabia. Paper presented at the Social Science Conference, Malaysia.

[7] Arslan, S., Savaser, S., Hallett, V. \& Balci, S. (2012). Cyberbullying among primary school students in Turkey: self-reported prevalence and associations with home and school life. Cyberpsychology, Behavior \& Social Networking, 15 (10), 527-533.

[8] Beaudoin, K. \& Schonert-Reichl, K. (2006). Epistemic reasoning and adolescent egocentrism: Relations to internalizing and externalizing symptoms in problem youth. Journal of Youth and Adolescence, 35, 9991014.

[9] Beck, A. (2008). The evolution of the cognitive model of depression and its neurobiological correlates. American Journal of Psychiatry, 165(8), 969-977

[10]Beck, J. \& Beck, A. (2011). Cognitive behavior therapy: Basics and beyond. New York: The Guilford Press.
[11] Belsey, B. (2008). WWW.cyberbullying.org: Always on, always aware. Retrieved July 13, 2020 from http://www.cyberbullying.org/

[12] Berson, I., Berson, M. \& Ferron, J. (2002) Emerging risks of violence in the digital age: Lessons for educators from an online study of adolescent girls in the united states. Meridian: A Middle School Computer Technologies Journal, 5 (2), 1-8.

[13] Bo-Abdullah, S. (2016). The effects of internet usage on adolescents' students. Unpublished Master Thesis, Mohammad Khider University, Algeria.

[14] Boury, M., Treadwell, T. \& Kumar, V. (2001). Integrating psychodrama cognitive therapy: An explanatory study. International Journal of Action Methods, 54, 13 - 28.

[15] Çelikkaleli, Ö. \& Kaya, S. (2016). University students' interpersonal cognitive distortions, psychological resilience, and emotional selfefficacy according to sex and gender roles. Pegem Ĕgitim ve Öğretim Dergisi, 6(2), 187212.

[16] Çetin, B., Peker, A., Eroğlu, Y. \& Çitemel, N. (2011). Interpersonal cognitive distortions as a predictor of cyber victimization and bullying: A preliminary report in adolescents. International Online Journal of Educational Sciences 3(3), 1064-1080.

[17] Çoban, A. \& Karaman, N. (2013). Üniversite Öğrencilerinin Umutsuzluk, Kaygı ve İlişkilerle İlgili Bilişsel Çarpıtmaları. Journal of Cognitive Behavioral Psychotherapy and Research, 2, 78-88

[18]Corey, G. (2016). Theory and practice of counseling and psychotherapy. United States: Cengage Learning.

[19]Dozois, D. \& Beck, A. (2008). Cognitive schemas, beliefs and assumptions. In K. S. Dobson \& D. J. A. Dozois (Eds.), Risk factors in depression (pp. 121-143). Oxford, United Kingdom: Elsevier/Academic Press.

[20]Engler, B. (2014). Personality theories. Australia: Wadsworth CENGAGE learning. 
[21] Erdur-Baker, Ö. \& Kavşut, F. (2007). A new face of peer bullying: Cyberbullying. Journal of Euroasian Educational Research, 27, 3142.

[22] Graham, M. (2014). Facts of Life: ten issues of contentment. Colorado: Outskirts Press.

[23] Gençdoğan, B. \& Çikrikci, Ö (2015). Reliability and validity studies of the Turkish version of the e-bullying scale (E-Bs) and evictimization scale (E-VS). Journal of Theory and Practice in Education, 11(1), 359-373.

[24] Craske, M. (2010). Cognitive-behavioral therapy. Washington, DC: American Psychological Association.

[25] Grohol, J. (2009). cognitive distortions. New York: Routledge Taylor \& Francis.

[26] Hamamc1, Z. \& Büyüköztürk, Ş. (2003). Ilişkilerle ilgili bilişsel çarpıtmalar ölçeği, ölçeğin geliştirilmesi ve psikometrik özelliklerinin incelenmesi. Çukurova Üniversitesi Eğitim Fakültesi Dergisi, 2(25), 107-111.

[27] Hamilton, D. (2015). Cognitive processes in stereotyping and intergroup behavior. London: Psychology Press.

[28] Helmond, P., Overbeek, G., Brugman, D., \& Gibbs, J. (2015). A meta-analysis on cognitive distortions and externalizing problem behavior. Criminal Justice and Behavior, 42 (3), 245-262.

[29] Holtz, J. (2011). Applied clinical neuropsychology. New York: Springer publishing company.

[30] Ishak, N., Jdaitawi, M., Ibrahim, Y., \& Mustafa, F. (2011). Moderating effect of gender and age on the relationship between emotional intelligence with social and academic adjustment among first year university students. International Journal of Psychological Studies, 3(1), 78-89.

[31] Ismael, A., Jdaitawi, M., \& Talafha, F. (2015). Towards a better investment of university students in light of the twentieth century challenges. International Educational Studies, 8(6), 113-123.

[32] Jdaitawi, M. (2020). Does flipped learning promote positive emotions in science education? A comparison between traditional and flipped classroom approaches. The Electronic Journal of e-Learning, 18(6), 516524.

[33] Jdaitawi, M. (2020). The effect of using problem-based learning upon students emotions towards larning and levels of communication skills in three different disciplines. Croatian Journal of Education, 22(1), 207-240. http://doi.org/10.15516/cje.v22i13215.

[34] Jdaitawi, M., Al-Mutawa, A., Musallam, F., \& Talafha, F. (2014). Stress and psychological strain among university lecturers in Saudi Arabia. Paper presented at the Global Conference on Business and Finance, 9(1).

[35] Jdaitawi, M. et al. (2013). Students perspectives on university experiences; the role of protective factors in students lives. International Education Studies, 6(7), 239246.

[36] Juvonen, J. \& Gross, E. (2008). Extending the school grounds?: Bullying experiences in cyberspace. The Journal of School Health, 78 (9), 496-505.

[37] Keefe, J., Chambless, D., Barber, J. \& Milrod, B. (2019).Treatment of anxiety and mood comorbidities in cognitive-behavioral and psychodynamic therapies for panic disorder. Journal of Psychiatric Research, 114, 34-40.

[38] Kendall, P. (1992). Healthy thinking. Behavior Therapy, 23, 1-11.

[39]Leahy, R. (2010). Bilişsel Terapi Yöntemleri (H. M. Türkçapar \& E. Köroğlu, Trans. 2 ed.). Ankara: HYB.

[40]Lenhart, A., Madden, M., Macgill, A. \& Smith, A. (2007). Teems and social media: The use of social media a gains a greater 
foothold in teem life as they embrace the conversational nature of interactive online media. PEW, interment \& American life project. Retrieved July,15, 2020, from https://www.pewinternet.org/wpcontent/uploads/sites/9/media/Files/Reports/ 2007/PIP_Teens_Social_Media_Final.pdf.pd $\underline{\mathrm{f}}$

[41]Leung, P. \& Poon, M. (2001). Dysfunctional schemas and cognitive distortions in psychopathology: A test of the specificity hypothesis. Journal Child Psychol. Psychiatry, 42(6),755-765.

[42] Li, Q. (2005). Cyberbullying in schools: Nature and extent of Canadian adolescents' experience. Paper presented at the Annual meeting of the American Educational Research Association Montreal, Canada.

[43] Malek, J. (2015). Social connectedness, academic, non-academic behaviors related to self-regulation among unievristy stduents in Saudi Arabia. Interantional Education Studies, 8(2), 84-100.

[44] Malek, J. (2019). The effect of flipped classroom strategy on students learning outcomes. International Journal of Instruction, 12(3), 665-680.

[45] Maya Panorama., \& Malek, J. (2011). Relationship between emotional intelligence and work-family conflict of university staff in Indonesia. Paper presented at the International Conference on Social Science, Economics and Arts, 14-15 January, Malaysia.

[46] Mishna, F., Mclukie, A. \& Saini, M. (2009). Real-world dangers in an online reality: A qualitative study examining online relationships and cyber abuse. Social Work Research, 33, 107-118.

[47] Nyarko, K. \& Amissah, C. (2014). Cognitive distortions and depression among undergraduate students. Research on Humanities and Social Sciences, 4 (4), 6975.
[48] Olweus, D. (2012). Cyberbullying: An overrated phenomenon?. European Journal of Developmental Psychology, 9 (5), 1-19.

[49] Owens, L., Skrzypiec, G. \& Wadham, B. (2014) Thinking patterns, victimisation and bullying among adolescents in a South Australian metropolitan secondary school. International Journal of Adolescence and Youth, 19 (2), 190-202

[50] Patchin, J. \& Hinduja, S. (2006). Bullies move beyond the schoolyard A preliminary look at cyberbullying. Youth Violence and Juvenile Justice, 4(2), 148-169.

[51] Ramadan, H. (2016). Factorial structure of cyberbullying scale as perceived by a sample of victim adolescent. Psychological Health Journal, 4, 40-85.

[52] Reema, A. (2010). Self-automatic judrnent aggression and hostility among a group of battered women in shelter house and nonbattered in Jeddah province. Unpublished Master Thesis, Umm Al-qura University, Saudi Arabia.

[53] Schwartz, P., Maynard, A. \& Uzelac, S. (2008). Adolescent egocentrism: A contemporary view. Adolescence, 43, 441448.

[54] Smith, P., Mahdavi, J., Carvalho, M. \& Tippett, N. (2006). An investigation into cyberbullying, its forms, awareness and impact, and the relationship between age and gender in cyberbullying. London: University of London, Goldsmiths college, Unit for school and family studies.

[55] Topcu, Ç. \& Erdur-Baker, Ö. (2010). The revised cyber bullying inventory (RCBI): Validity and reliability studies. Procedia Social \& Behavioral Sciences, 5, 660-664.

[56] Weary, G. \& Edwards, J. (1994). Social cognition and clinical psychology: Anxiety, depression, and the processing of social information. In S. Wyer \& T. K. Srull (Eds.), Handbook of social cognition (2nd ed.). Hillsdale, NJ: Erlbaum. 
[57] Willard, N. (2007). Cyber bullying and cyber threats. Champaign, IL: Research Press.

[58] Willard, N. (2003). Off-campus, harmful online student speech. Journal of School Violence, 1 (2), 65-93.

[59] Ybarra, M. \& Mitchell, K. (2004) Online aggressor/targets, aggressors and targets: A comparison of associated youth characteristics. Journal of Child Psychology and Psychiatry, 45 (7), 1308-1316.

[60] Ybarra, M., Mitchell, K., Finkelhor, D. \& Wolak, J. (2007) Internet Prevention messages: Targeting the right online behaviors. Archives of Pediatric Adolescence Medicine, 161 (4), 138-145.

[61] Young, J. (2005). Young schema questionnaire - Short form 3 (YSQ-S3). New York: Cognitive Therapy Center.

[62] Zhou, Z., Tang, H., Tian, Y., Wei, H. Zhang, F. \& Morrison, C. (2013). Cyberbullying and its risk factors among Chinese high school students. School Psychology International, 34 (6), 630-647. 